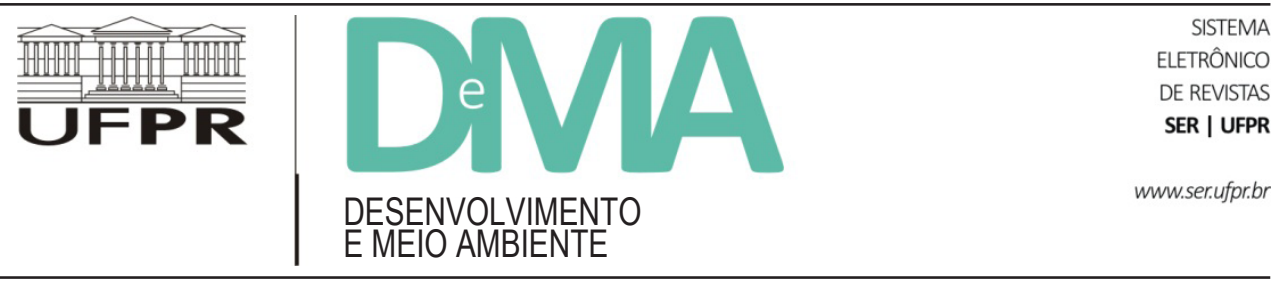

\title{
Licenciamento ambiental simplificado na região sudeste brasileira: conceitos, procedimentos e implicações
}

\section{Simplified Environmental Licensing in Brazil's Southeastern States: Concepts, Procedures and Implications}

\author{
Francysmary Sthéffany Dias OLIVEIRA ${ }^{1}$, José Francisco do PRADO FILHO ${ }^{2}$, Caroline Fan ROCHA ${ }^{1}$, Alberto \\ FONSECA $^{2 *}$ \\ ${ }^{1}$ Secretaria de Estado de Meio Ambiente e Desenvolvimento Sustentável de Minas Gerais, Belo Horizonte, MG, Brasil. \\ ${ }^{2}$ Departamento de Engenharia Ambiental, Escola de Minas, Universidade Federal de Ouro Preto (UFOP), Outro Preto, MG, Brasil. \\ *E-mail de contato: albertof@em.ufop.br
}

Artigo recebido em 29 de julho de 2015, versão final aceita em 27 de julho de 2016.

RESUMO: O licenciamento ambiental, apesar da sua relevância como instrumento de política ambiental, é frequentemente criticado como moroso e burocrático. Em reação a tais críticas, diversos órgãos licenciadores têm promovido ações de simplificação no uso desse instrumento. Este artigo teve por objetivo analisar os conceitos e os modelos de licenciamento ambiental simplificado nos estados da região sudeste, de modo a entender suas implicações para o processo decisório. O estudo seguiu uma abordagem metodológica qualitativa e descritiva, com dados coletados por meio de consultas às legislações estaduais e aos websites dos órgãos licenciadores estaduais. Observou-se que a simplificação do licenciamento ambiental tem se dado, sobretudo, pela isenção ou simplificação dos estudos ambientais, bem como na redução no número de etapas e trâmites no licenciamento. A simplificação do licenciamento de projetos tem contribuído para desvincular a Avaliação de Impacto Ambiental do licenciamento ambiental, na medida em que este passa a ser conduzido sem o apoio daquele. Também ficou evidente que a simplificação pode diminuir o grau de precaução do processo, ao diminuir o volume de informações e ritos de análise e participação pública. Todavia, os procedimentos simplificados podem agilizar a concessão de licenças e reduzir os custos do processo. $\mathrm{O}$ artigo conclui com uma discussão das potenciais consequências da simplificação e com sugestões de estudos futuros.

Palavras-chave: licenciamento ambiental; avaliação de impacto ambiental; licenciamento ambiental simplificado; região sudeste; política ambiental.

ABSTRACT: Environmental licensing is frequently criticized as time-consuming and excessively bureaucratic. In reaction, many public agencies have been promoting simplified approaches to licensing. This article analyzed a number of simplified models of environmental licensing in Brazil's southeastern states. This study adopted a qualitative and descriptive methodological approach, based on data collected from state legislation and websites. It was found 
that simplified licensing leads to a decision-making processes that exempts environmental impact studies, and reduces the number of procedures in the process. The simplified model is decoupling environmental licensing from environmental impact assessment. It was also found that the simplified model, while reducing the degree of precaution in decision-making, may speed up the process and reduce costs to the State and entrepreneurs. The study concludes with a discussion of the implications of such models and suggesting research avenues.

Keywords: environmental licensing; environmental impact assessment; streamlined environmental licensing; southeastern Brazil; environmental policy.

\section{Introdução}

Dentre os instrumentos da Política Nacional do Meio Ambiente (Brasil, 1981), a avaliação de impacto ambiental (AIA) e o licenciamento ambiental são aqueles que mais se consolidaram. Em meados dos anos 70, o licenciamento e a AIA eram utilizados apenas em algumas jurisdições brasileiras (Moreira, 1988). Atualmente, a União, os estados e centenas de municípios licenciam regularmente diversas tipologias de empreendimentos potencialmente poluidores. Embora não haja estatísticas oficiais, os dados dos diversos órgãos licenciadores brasileiros sugerem que dezenas de milhares de licenças ambientais sejam emitidas anualmente. $\mathrm{O}$ crescimento da emissão de licenças ambientais tem sido acompanhado por um aumento no número de leis, regulamentos, procedimentos e normas ambientais (Hofmann, 2015).

A concessão de licenças ambientais amparada por estudos de impacto ambiental tem contribuído para o aprimoramento de projetos e para a mitigação de impactos ambientais (Sánchez, 2013). Todavia, esses benefícios são ofuscados por um crescente debate sobre a ineficiência do sistema. Dentre os aspectos mais salientes desse debate estão as questões da morosidade e da burocracia. Empreendedores, associações industriais e consultores há muito criticam as crescentes exigências dos estudos e procedimentos licenciatórios (Câmara dos Deputados, 2015; CNI, 2007; Aguilar, 2008;
Banco Mundial, 2008; CNI, 2011; SEBRAE, 2011). Um estudo da Secretaria de Assuntos Estratégicos da Presidência da República (SAE) salienta que o licenciamento ambiental ainda é marcado por demoras injustificadas, exigências burocráticas excessivas, decisões pouco fundamentadas, insensatez desenvolvimentista de empreendedores e contaminação ideológica do processo (SAE, 2009). Tal percepção foi recentemente corroborada pela presidente do Instituto Brasileiro do Meio Ambiente e dos Recursos Naturais Renováveis (IBAMA), que afirmou ser "[...] necessário fazer uma requalificação do licenciamento ambiental, retirando certos excessos e complementando lacunas" (Borges, 2015).

Os órgãos ambientais licenciadores, nos três níveis da federação, têm respondido a essas críticas com uma série de ações de simplificação. Um dos principais regulamentos vigentes do licenciamento ambiental, a Resolução $n^{\circ}$ 237/97 do Conselho Nacional do Meio Ambiente (CONAMA) (Brasil, 1997), em seu artigo 12, deixa clara a legalidade dessas ações:

[...] $\S 1^{\circ}$ - Poderão ser estabelecidos procedimentos simplificados para as atividades e empreendimentos de pequeno potencial de impacto ambiental, que deverão ser aprovados pelos respectivos Conselhos de Meio Ambiente;

$\S 2^{\circ}$ - Poderá ser admitido um único processo de licenciamento ambiental para pequenos empreendimentos e atividades similares e vizinhos ou para aqueles integrantes de planos de desenvolvimento aprovados, previamente, pelo órgão governamental 
competente, desde que definida a responsabilidade legal pelo conjunto de empreendimentos ou atividades; e

$\S 3^{\circ}$ - Deverão ser estabelecidos critérios para agilizar e simplificar os procedimentos de licenciamento ambiental das atividades e empreendimentos que implementem planos e programas voluntários de gestão ambiental, visando à melhoria contínua e o aprimoramento do desempenho ambiental (Brasil, 1997, art. 12).

Apesar do aceno legal e da considerada importância da simplificação do licenciamento, sobretudo às atividades e empreendimentos de baixo potencial de impacto, é reduzido o número de estudos no Brasil que abordaram este tema. Esta situação é considerada preocupante, tendo em vista que o Ministério Público de alguns estados e alguns autores e instituições têm questionado a efetividade dos processos e estudos simplificados de licenciamento ambiental (Ribeiro, 2004; Kirchhoff et al., 2007; Montaño \& Sousa, 2008; Rodrigues, 2010; Porto, 2010; 2011; Procuradoria da República do Ceará, 2011; Moraes, 2013). Preocupações similares também foram levantadas em contextos internacionais (Bond et al., 2014; Kirchhoff \& Tsuji, 2014).

Diante da crescente relevância deste tema, este estudo procurou analisar e comparar os conceitos e os modelos de licenciamento ambiental estadual simplificado na região sudeste brasileira, de modo a entender em que medida tais procedimentos podem afetar o processo decisório e o acompanhamento das licenças ambientais. Espera-se que a exposição das principais diferenças e semelhanças identificadas contribua para um fortalecimento conceitual do "licenciamento ambiental simplificado", que poderá ser útil não apenas para acadêmicos, mas também para legisladores e gestores públicos interessados no aprimoramento administrativo dos sistemas de AIA e licenciamento ambiental.

\section{Abordagem metodológica}

Este estudo seguiu uma abordagem metodológica qualitativa, baseada em uma análise detalhada da legislação ambiental estadual, sobretudo referente aos critérios de enquadramento (triagem) e termos de referência (escopo) dos empreendimentos, bem como dos procedimentos e estudos licenciatórios simplificados disponíveis nos websites dos quatro órgãos ambientais da região sudeste brasileira, a saber: Superintendências Regionais de Regularização Ambiental (SUPRAMs), de Minas Gerais; Companhia Ambiental do Estado de São Paulo (CETESB), de São Paulo; Instituto Estadual do Ambiente (INEA), do Rio de Janeiro; e Instituto Estadual de Meio Ambiente e Recursos Hídricos (IEMA), do Espírito Santo. As análises se deram no período de novembro de 2013 a dezembro de 2014 e se pautaram pela identificação dos procedimentos e legislações disponíveis nos websites. Nesta pesquisa, analisamos os procedimentos e modelos simplificados de licenciamento ambiental aplicáveis, sobretudo, às fases de pré-instalação dos empreendimentos. Obviamente existem modelos de regularização e licenciamento "corretivo", mas estes não foram abordados aqui.

O sudeste brasileiro é a região com a maior densidade demográfica e possui o mais alto índice de urbanização e industrialização do Brasil. Abrange maior diversidade, acumulação e sinergia dos impactos ambientais desencadeados por atividades econômicas e de desenvolvimento, sendo, portanto, a região com maior demanda por licenciamentos ambientais no país. A conjunção desses aspectos (desenvolvimento, crescimento econômico, intensificação dos problemas ambientais e diversificação de estudos e instrumentos ambientais) estimula a abordagem do presente estudo, tendo como foco 
os diferentes procedimentos de licenciamento ambiental simplificado de empreendimentos de pequeno porte e potencial poluidor. A escolha da região sudeste também se justifica pelo fato de os sistemas de licenciamento desta região servirem, há décadas, como fonte de inspiração para outros estados brasileiros.

\section{A tendência da simplificação dos processos e estudos de AIA e Licenciamento Ambiental}

O National Environmental Policy Act (NEPA), publicado em 1969 nos Estados Unidos, é frequentemente citado como o primeiro exemplo de legislação mundial que tornou obrigatória a avaliação de impacto ambiental por agentes governamentais. O NEPA, que é de certa forma análogo à Política Nacional do Meio Ambiente (PNMA) brasileira de 1981, serviu de inspiração para vários países tornarem as AIAs mandatórias em seus territórios (Wathern, 1990). Dos 193 países membros das Nações Unidas, 191 têm alguma forma de exigência de AIA em seu território (Morgan, 2012). Uma das definições mais citadas de AIA é a da Associação Internacional para Avaliação de Impacto (sigla IAIA em inglês): “[...] o processo de identificar, prever, avaliar e mitigar os efeitos biofísicos e sociais de propostas de desenvolvimento, antes que decisões e acordos sejam feitos" (Senécal et al., 1999, p. 1).

Dentre as primeiras leis que fizeram menção à AIA no Brasil está a já citada PNMA (Lei n. 6.938/81), que incluiu a AIA, juntamente com licenciamento ambiental, entre os principais instrumentos da política ambiental brasileira. Com a Resolução CONAMA 01/86, o licenciamento ambiental tornou-se fortemente vinculado à AIA, ao exigir estudos de impacto ambiental (EIA) e seu respectivo Relatório de Impacto Ambiental (RIMA) para subsidiar decisões acerca da concessão ou não de licenças ambientais para diversas tipologias de projeto. O processo de licenciamento ambiental, que objetiva licenciar atividades ou empreendimentos "[...] utilizadores de recursos ambientais, efetiva ou potencialmente poluidores ou capazes, sob qualquer forma, de causar degradação ambiental" (Brasil, 1997, art. $1^{\circ}$ ), tem sido desde então confundido com processo de AIA. No Brasil, é comum o tratamento dos dois instrumentos como sinônimos, apesar de terem funções diferenciadas. Obviamente, pode-se conduzir uma AIA para subsidiar, por exemplo, decisões de financiamento de projetos ou implementação de políticas públicas ou setoriais que não sejam relacionadas à concessão de licença; da mesma forma, pode-se licenciar atividades e empreendimentos sem o subsídio de avaliações de impacto, mas com base em cadastros e documentação de controle (Fonseca, 2015).

$\mathrm{O}$ processo de licenciamento, quando vinculado à avaliação de impacto, pode ser resumido nas seguintes etapas sequenciais: 1) proposta de projeto ou atividade, 2) triagem das propostas, 3) determinação do escopo dos estudos, 4) elaboração dos estudos de identificação e predição de impacto ambiental, 5) análise dos estudos, 6) decisão sobre a concessão da licença, e 7) acompanhamento dos compromissos e condicionantes da licença ambiental. Uma oitava etapa, a participação pública, deveria permear todas as sete etapas básicas (Dietz, 2008). No Brasil, conforme ilustra a Figura 1, essas etapas se multiplicam, pois a legislação prevê no licenciamento convencional ou ordinário, i.e., não simplificado, a necessidade de obtenção de Licença Prévia (LP), Licença de Instalação (LI) e Licença de Operação (LO). Para a obtenção da LP é necessária a elaboração do supramencionado EIA/ RIMA. Além disso, no Brasil, a participação pública 


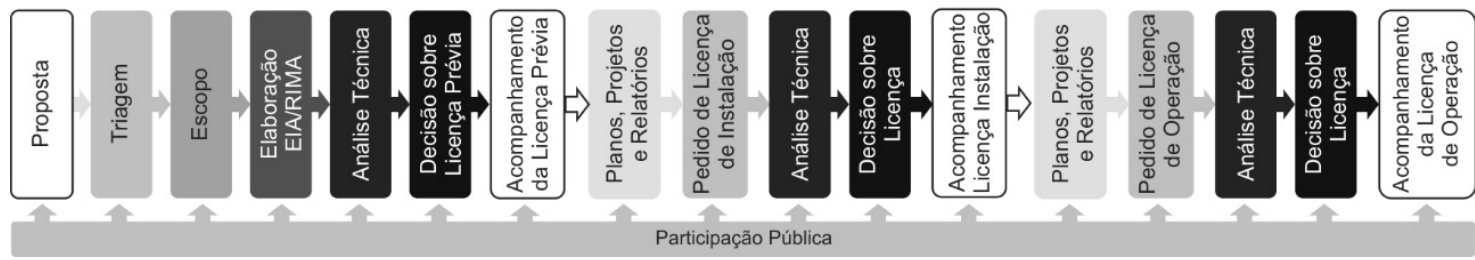

FIGURA 1 - Principais etapas do processo trifásico de Licenciamento Ambiental convencional ou ordinário. FONTE: Adaptado de Fonseca (2015).

é reduzida, sendo frequentemente confundida com a audiência pública, a qual, como apontaram Ribeiro e Pinheiro (2011), reflete apenas um tipo de participação que se dá ao final da etapa de elaboração dos estudos de impacto.

O modelo convencional de licenciamento ambiental trifásico com EIA/Rima demanda um rito procedimental mais longo e com maiores exigências de estudos e documentos, quando comparado a modelos de licenciamento que exigem, por exemplo, uma única licença de operação. Esse modelo convencional, com origem nas Resoluções CONAMA 01/1986 e 237/1997, foi mais claramente pensado para o licenciamento de empreendimentos com grande potencial de impacto ambiental. Todavia, por motivos diversos, como, por exemplo, a falta de normatização de parâmetros relacionados à vulnerabilidade do meio, de porte e potencial poluidor, este modelo foi sendo aplicado a diversos tipos de empreendimentos, inclusive àqueles com pequeno potencial de impacto.

Essa "desproporcionalidade" entre o grau de exigência do licenciamento ambiental e o potencial de impacto dos projetos submetidos a licenciamento ambiental é uma das principais causas do acúmulo de processos de licenciamento ambiental à espera de análise técnica dos órgãos licenciadores, que, historicamente, trabalham com limitações de infraestrutura e pessoal. Essa situação, que acarreta a formação de passivos de processos administrativos de licenciamento nos órgãos públicos, ainda não foi devidamente tratada na literatura acadêmica. Todavia, a imprensa há anos divulga a existência desse passivo, que aparenta ser um dos principais fatores motivadores para a implantação dos modelos simplificados de licenciamento ambiental. Nesta pesquisa, foram identificadas notícias relatando a existência de passivos de processos de licenciamento ambiental e iniciativas de simplificação nos estados de Amazonas, Espírito Santo, Goiás, Minas Gerais, Rio Grande do Norte, Rio Grande do Sul e Santa Catarina (Prefeitura de Manaus, 2010; Governo do Espírito Santo, 2013; Dantas, 2014; Tudo Sobre Floripa, 2014; Goiânia, 2015; O Tempo, 2015; Pereira, 2015). Recentemente, o Estado do Rio de Janeiro, por meio do Decreto Estadual 45.482/15, reconheceu, de forma explícita, "a existência de um grande passivo em relação ao número de processos de licenciamento ambiental em trâmite no órgão ambiental estadual", que motivava a instauração de sistemas simplificados de licenciamento ambiental.

A legislação federal brasileira, apesar de permitir a simplificação no processo de licenciamento, não é clara em relação ao conceito e à forma desejável do licenciamento ambiental simplificado. A supracitada Resolução CONAMA 237/97, por meio do seu artigo 12, sugere que a simplificação 
é desejada nos casos de empreendimentos com pequeno potencial de impacto ambiental e de empreendimentos que adotem programas voluntários socioambientais. Nessa linha, entre 2001 e 2010, o CONAMA publicou ao menos oito resoluções (e.g. resoluções 279/2001, 334/2003, 335/2003, 349/2004, 377/2006, 385/2006, 404/2008 e $412 / 2009$ ), que estabeleceram procedimentos simplificados de licenciamento ambiental para algumas tipologias de projetos de pequeno potencial de impacto. Todavia, mais recentemente, o Ministério do Meio Ambiente, por meio de um conjunto de portarias próprias e interministeriais, estabeleceu diversos procedimentos simplificados de licenciamento ambiental aplicáveis inclusive a empreendimentos de médio e grande potencial de impacto. Essas portarias visam à simplificação do licenciamento ambiental de diversos tipos e portes de projetos de infraestrutura, como sistemas de transmissão de energia elétrica, rodovias federais, terminais portuários e plataformas de exploração de óleo e gás (Brasil, 2011a; b; c; d; e; f). As portarias do MMA especificaram prazos e condições para manifestação de órgãos envolvidos no licenciamento ambiental, bem como modelos alternativos de estudos ambientais, licenciamento conjunto de grupos de empreendimentos, dentre outros mais. As motivações e os efeitos dessas novas normas ainda foram pouco explorados na literatura acadêmica. Todavia, é razoável argumentar, como fez recentemente Borges (2015), que há, por trás desses novos modelos de simplificação, uma clara motivação política visando ao desenvolvimento econômico e industrial de alguns grupos de interesse.

Iniciativas de simplificação do licenciamento ambiental também estão ocorrendo nos níveis estaduais, onde há uma crescente legislação disciplinando a simplificação de trâmites, estudos, termos de referência, dentre outros requisitos aplicáveis ao licenciamento ambiental. As abordagens de simplificação variam significativamente entre jurisdições. Como evidencia a seção seguinte, mesmo na região sudeste, há uma pluralidade de abordagens.

\section{O Licenciamento Ambiental Simplificado na região sudeste}

\subsection{Licenciamento Ambiental Simplificado no Espírito Santo}

O licenciamento estadual de projetos propostos no Estado do Espírito Santo é realizado pela Gerência de Controle Ambiental (GCA) do Instituto Estadual de Meio Ambiente e Recursos Hídricos (IEMA) (IEMA, 2014). No Espírito Santo, um dos mais conhecidos procedimentos de licenciamento ambiental simplificado é orientado pela IN 12/08, que "dispõe sobre a classificação de empreendimentos e definição dos procedimentos relacionados ao licenciamento ambiental simplificado". As atividades passíveis de licenciamento simplificado devem requerer junto ao órgão licenciador a Licença Simplificada (LS), definida como:

\begin{abstract}
[...] ato administrativo de procedimento simplificado pelo qual o órgão ambiental emite apenas uma licença, que consiste em todas as fases do licenciamento, estabelecendo as condições, restrições e medidas de controle ambiental que deverão ser obedecidas pelo empreendedor para localizar, instalar, ampliar e operar empreendimentos ou atividades utilizadoras de recursos ambientais, considerados de baixo impacto ambiental que se enquadrarem na Classe Simplificada [...] (CONSEMA, 2008).
\end{abstract}

O licenciamento simplificado, segundo IEMA (2008), tem como objetivo facilitar o acesso dos pequenos empreendimentos ao licenciamento e a 
agilização no processo. Tal licença deve ser requerida na fase de localização do empreendimento, podendo também ser emitida para empreendimentos em funcionamento, desde que os mecanismos de controle ambiental estejam de acordo com a legislação vigente. A IN 12/08, em seu anexo I, relaciona os grupos de atividades passíveis de licenciamento simplificado. O principal critério utilizado para o enquadramento desses grupos passíveis de licenciamento simplificado é o porte do empreendimento. Além desses critérios, a IN 12/08 definiu critérios gerais e mais específicos de enquadramento, relacionados às condições de localização do empreendimento, ao método construtivo, à forma de gerenciamento ambiental, aos tipos de sistemas de controle ambiental, dentre outros. As atividades relacionadas no anexo I da IN $\mathrm{n}^{\circ} 12 / 08$ que atendam aos critérios de porte e aos critérios gerais e específicos ficam, portanto, enquadradas no licenciamento simplificado.

O licenciamento simplificado regulado pela IN 12/08 dá-se através da emissão de uma única licença, a já mencionada LS, dispensando, portanto, o rito mais longo de obtenção das licenças prévia, de instalação e de operação. Para a formalização do processo simplificado, não são exigidos estudos de impacto ambiental, mas tão somente os documentos relacionados no Artigo 11 da IN 12/08. Dentre esses documentos, têm destaque o Termo de Responsabilidade Ambiental (TRA) e a respectiva Anotação de Responsabilidade Técnica (ART), por meio dos quais o empreendedor e o técnico responsável declaram operar as atividades de acordo com a legislação ambiental vigente.

Outra questão procedimental vinculada a este tipo de licenciamento simplificado é a possibilidade de solicitar a LS para diversas tipologias, por meio do site do IEMA, sem que o empreendedor ou o responsável técnico precise comparecer à sede do órgão no município de Cariacica (ES). Esta determinação é particularmente relevante no caso do IEMA, tendo em vista que este órgão não possui escritórios regionais disponíveis para protocolização de documentos vinculados ao licenciamento ambiental.

Além da LS, o IEMA também prevê a possibilidade de elaboração de tipos simplificados de estudos de impacto ambiental para alguns casos e tipologias de atividades. Destacam-se o Relatório Ambiental Preliminar (RAP) e o Plano de Controle Ambiental (PCA).

\subsection{Licenciamento Ambiental Simplificado em Minas Gerais}

Em Minas Gerais, os órgãos executivos responsáveis pelo licenciamento ambiental estadual são as nove unidades das Superintendências Regionais de Regularização Ambiental (SUPRAMs) e seus Núcleos Regionais de Regularização Ambiental (SEMAD, 2014). O processo de enquadramento de porte e potencial poluidor em Minas Gerais é regulamentado pela Deliberação Normativa do Conselho Estadual de Política Ambiental - (DN COPAM) $n^{\circ} 74 / 04$. Os empreendimentos ou obras são enquadrados pelo cruzamento de porte (pequeno, médio e grande) e pelo potencial poluidor e/ ou degradador (pequeno, médio e grande), enquadrando as atividades nas classes 1, 2, 3, 4, 5 ou 6 (Minas Gerais, 2004).

A "simplificação do licenciamento ambiental" de Minas Gerais não é tão explícita como no Espírito Santo. A legislação não utiliza o termo "licença simplificada", mas, na prática, utiliza uma modalidade de autorização, a "Autorização Ambiental de Funcionamento (AAF)", regulada pela DN COPAM 74/04, que é claramente comparável a uma tipologia 
de licenciamento ambiental simplificado (Moraes, 2013). Podem obter a AAF apenas empreendimentos enquadrados nas Classes 1 e 2, considerados, na legislação de Minas Gerais, como causadores de "impacto ambiental não significativo" (Minas Gerais, 2004).

O processo que envolve a obtenção da AAF é profundamente mais simplificado e rápido do que o licenciamento convencional, pois não exige a apresentação de estudos de impacto ambiental ou outro estudo qualquer. A principal documentação exigida na formalização do processo de AAF é o Termo de Responsabilidade do Empreendedor e a Anotação de Responsabilidade Técnica (ART) do profissional que se responsabilizou pelo gerenciamento ambiental do empreendimento junto ao órgão ambiental (Viana \& Bursztyn, 2010; Moraes, 2013). Nesse procedimento, o empreendedor deve unicamente preencher o Formulário de Caracterização do Empreendimento (FCE) e apenas ele servirá como documento referencial para uma eventual fiscalização ao empreendimento (Viana, 2007; Moraes, 2013).

O órgão ambiental de Minas Gerais, para a concessão da AAF, não faz vistoria ou checagem do local para constatação das informações fornecidas pelo empreendedor. Moraes (2013) sustenta ainda que a fiscalização por parte do órgão ambiental dos empreendimentos detentores da AAF é tarefa de difícil execução devido à ausência de estudos ambientais e à falta de documentação relativa às ações de controle e monitoramento ambiental eventualmente propostas/executadas pelo empreendedor. Viana \& Bursztyn (2010) complementam que a introdução da AAF em Minas Gerais trouxe complicadores, pois, apesar de a AAF agilizar a regularização ambiental dos empreendimentos, na prática excluiu os estudos ambientais do processo, incorrendo-se no risco de autorizar empreendimentos em locais e situações inadequados.

A AAF reflete um tipo de simplificação de licenciamento ambiental voltada principalmente para atividades de pequeno potencial poluidor, aos moldes da LS no Espírito Santo e em consonância com o Artigo 12 da Resolução CONAMA 237/1997. Todavia, a DN COPAM 74/04, apesar de não usar o termo "simplificado", prevê um rito mais ágil de licenciamento para as classes 3 e 4 desta DN COPAM, que incluem empreendimentos enquadrados em faixas mais intermediárias de potencial de impacto. Nesses casos, as licenças prévia e de instalação podem ser expedidas concomitantemente, tornando o processo potencialmente mais ágil. Nesses casos, porém, são mantidas as exigências de estudos ambientais, que geralmente são versões simplificadas de estudos, como o Relatório de Controle Ambiental (RCA) e o Plano de Controle Ambiental (PCA). Em Minas Gerais, não há a possibilidade de protocolização digital, via site, de formulários, documentos e estudos.

Durante a redação deste artigo, em janeiro de 2016, o Estado de Minas Gerais publicou a Lei 21.972/16, que previu um novo tipo de licença, a Licença Ambiental Simplificada (LAS), que substituirá a AAF por um modelo autodeclaratório que exige um melhor controle dos dados fornecidos pelos empreendedores (Minas Gerais, 2016). A lei ainda não foi implementada, mas corrobora a importância da simplificação no Estado.

\subsection{Licenciamento Ambiental Simplificado no Rio de Janeiro}

No Estado do Rio de Janeiro, o Instituto Estadual do Ambiente (INEA), por meio de Superintendências Regionais, é responsável pelo 
licenciamento ambiental estadual (INEA, 2014). O processo de enquadramento dos empreendimentos sujeitos ao licenciamento é regulamentado, sobretudo, pelo Decreto Estadual 44.820/14, alterado recentemente pelo Decreto Estadual 45.482/15, e pelas Resoluções INEA 52/12 e 53/12. Este decreto dispõe sobre o Sistema de Licenciamento Ambiental (SLAM) e seu respectivo Anexo 1 apresenta uma lista de atividades enquadradas nas Classes 1 a 6 , conforme o porte (mínimo, pequeno, médio, grande e excepcional) e potencial poluidor (insignificante, baixo, médio e alto), de acordo com os parâmetros e limites das Resoluções INEA 52/12 e 53/12. Os projetos sujeitos ao licenciamento simplificado são, essencialmente, os enquadrados como de "baixo impacto", classificação que pode incluir empreendimentos de médio e grande portes, mas que, necessariamente, sejam classificados na legislação estadual como de baixo impacto. Os empreendimentos que se enquadrarem nesta condição poderão solicitar a Licença Ambiental Simplificada (LAS), que, como define o decreto, é

[...] concedida antes de iniciar-se a implantação do empreendimento ou atividade e, em uma única fase, atesta a viabilidade ambiental, aprova a localização e autoriza a implantação e a operação de empreendimento ou atividade classificado como de baixo impacto ambiental, com base nos critérios definidos no art. 23 deste Decreto, bem como daqueles definidos em regulamento específico, estabelecendo as condições e medidas de controle ambiental que deverão ser atendidas [...] (Rio de Janeiro, 2014).

A documentação e os estudos necessários para a formalização do pedido de LAS não são claramente apresentados na legislação estadual do Rio de Janeiro, como acontece nos Estados do Espírito Santo e de Minas Gerais. No caso do INEA, a documentação dependerá dos parâmetros do projeto, que devem ser informados via sistema online disponível no site do INEA. Dentre os estudos que podem, eventualmente, ser exigidos, destaca-se o Relatório Ambiental Simplificado (RAS): um tipo de estudo de impacto ambiental mais simplificado do que o EIA/Rima. Como acontece em Minas Gerais, o Rio de Janeiro, por meio do Decreto 44.820/14, prevê modelos de licenciamento bifásicos, que permitem a emissão concomitante ou da licença prévia e de instalação (LPI) ou da licença de instalação e de operação (LIO).

Mais recentemente, o Conselho Estadual de Meio Ambiente (CONEMA) publicou sua resolução 69 de 16 de dezembro de 2015, na qual estabeleceu o procedimento simplificado de licenciamento ambiental, que, de acordo com esta resolução, é:

[...] o trâmite por meio do qual a emissão ou renovação do documento de licenciamento previsto na legislação ocorre diretamente após a apresentação de documentos previamente definidos e a verificação da localização da atividade ou empreendimento, estabelecendo-se condições de validade antecipadamente especificadas, assumindo o requerente toda a responsabilidade pelas informações prestadas (CONEMA, 2015).

Este novo procedimento, ainda em implantação, deverá se assemelhar à AAF de Minas Gerais e à LS do Espírito Santo, na medida em que instaura um novo modelo autodeclaratório de licenciamento para atividades de pequeno impacto.

\subsection{Licenciamento Ambiental Simplificado em São Paulo}

No Estado de São Paulo, o licenciamento estadual de empreendimentos é realizado pela Companhia Ambiental do Estado de São Paulo (CETESB) e suas agências ambientais da região metropolitana 
de São Paulo e do interior do Estado. O Departamento de Avaliação de Impacto Ambiental (DAIA) é responsável pela análise dos estudos ambientais e pela elaboração dos pareceres técnicos que subsidiam o licenciamento com avaliação de impacto ambiental (CETESB, 2014a). A Resolução SMAn ${ }^{\circ}$ 54/04, dentre outras, dispõe sobre os procedimentos regulamentares para o licenciamento ambiental no Estado de São Paulo.

$\mathrm{O}$ enquadramento de empreendimentos sujeitos ao licenciamento ambiental em São Paulo é baseado, principalmente, na Lei Estadual 997/76 (aprovada pelo Decreto Estadual 8.468/76 e alterada pelo Decreto 47.397/02). No Artigo 57 do Decreto 8.468/76 consta uma lista de atividades consideradas "fontes de poluição", passíveis de licenciamento estadual no modelo trifásico (LP + LI + LO) ou, eventualmente, no modelo bifásico, com solicitação concomitante de licenças prévia e de instalação (São Paulo, 2002). O anexo 9 do Decreto 8.468/76 também apresenta uma lista de atividades que, caso atendam a uma série de critérios, podem solicitar licença ambiental na Região Metropolitana de São Paulo por meio do Sistema de Licenciamento Simplificado (SILIS), que, conforme a CETESB (2014b), é:

[...] um sistema informatizado, calcado na certificação digital, onde empreendimentos de baixo potencial poluidor podem, via Internet, obter o seu licenciamento ambiental por meio de um procedimento simplificado, no qual os documentos Licença Prévia, Licença de Instalação e Licença de Operação serão concedidos com a emissão de apenas um documento. [...] Todas as ações envolvidas neste procedimento são desencadeadas sem a necessidade do usuário comparecer às Agências Ambientais.

O SILIS surgiu pela necessidade de simplificação e desburocratização do licenciamento ambiental para as atividades ou empreendimentos de baixo potencial poluidor (SEBRAE, 2011). Da utilização do SILIS, chama maior atenção a agilidade no processo, cuja licença, segundo o Estado, pode ser obtida em até 15 dias. A principal desvantagem do sistema é a precária fiscalização preventiva do empreendimento na ocasião da solicitação do licenciamento, sendo que, na maior parte das vezes, ela ocorre por amostragem (CETESB, 2014a). Nota-se que nesse tipo de licenciamento não há exigência de estudos ambientais.

A Lei 997/76 e demais regulamentos do licenciamento estadual de São Paulo, em vez de utilizar critérios de enquadramento baseados em porte e potencial poluidor, como nos casos do Espírito Santo, Minas Gerais e Rio de Janeiro, dão preferência à terminologia "fator de complexidade", representada pela letra "W". Os tipos de licença, formulários, estudos, prazos de validade de licença, dentre outras questões do licenciamento ambiental estadual, variam de acordo com o fator de complexidade das atividades.

O Estado de São Paulo, diferentemente do Espírito Santo e do Rio de Janeiro, não emite uma licença denominada "simplificada". Todavia, há a possibilidade de o órgão ambiental exigir uma série de procedimentos simplificados, principalmente nos casos em que o licenciamento se dá sem o apoio da avaliação de impacto ambiental.

Em São Paulo, também podem ser exigidos estudos que, quando comparados ao EIA/RIMA, são mais simplificados. São os casos, por exemplo, do Estudo Ambiental Simplificado (EAS), utilizado para certo casos de projetos considerados de baixo potencial de degradação ambiental, e do Relatório Ambiental Preliminar (RAP), aplicável a projetos considerados potencialmente causadores de degradação do meio ambiente. 


\subsection{Síntese e análise comparada dos modelos simplificados}

A Tabela 1 abaixo sintetiza os principais aspectos dos modelos de licenciamento ambiental simplificado identificados nos estados da região sudeste.

Os procedimentos e regulamentos de licenciamento ambiental simplificado analisados nos quatro estados, de maneira geral, objetivam simplificar as fases do processo e os estudos e documentos. Nos modelos simplificados analisados, o processo trifásico de licenciamento ambiental, ilustrado na Seção 3 deste artigo, é substituído por um processo monofásico, no qual o Estado autoriza concomitantemente a viabilidade ambiental e locacional, bem como a instalação e a operação dos empreendimentos classificados como de baixo potencial de impacto. Em alguns casos, também são permitidos modelos bifásicos, nos quais há emissão concomitante de dois tipos de licenças.

Os tipos de estudos exigidos nos processos podem variar. Todavia, percebe-se que o EIA/RIMA tende a ser dispensado, dando lugar à apresentação de documentos técnicos, memoriais, projetos, termos e/ou versões simplificadas de estudos de impacto, como o RAP, PCA, etc. No Estado de Minas Gerais, no caso da AFF, a simplificação da exigência documental chega ao extremo, sendo solicitado basicamente Termo de Compromisso e Anotação de Responsabilidade Técnica (ART).

TABELA 1 - Principais regulamentos, terminologia e fases identificados nos modelos simplificados de licenciamento ambiental prévio nos estados da região sudeste.

\begin{tabular}{|c|c|c|c|c|}
\hline $\begin{array}{c}\text { Aspectos } \\
\text { analisados }\end{array}$ & $\begin{array}{l}\text { Espírito Santo } \\
\text { (IEMA) }\end{array}$ & $\begin{array}{l}\text { Minas Gerais } \\
\text { (SUPRAMs) }\end{array}$ & $\begin{array}{l}\text { Rio de Janeiro } \\
\text { (INEA) }\end{array}$ & $\begin{array}{l}\text { São Paulo } \\
\text { (CETESB) }\end{array}$ \\
\hline $\begin{array}{l}\text { Principal base } \\
\text { regulatória }\end{array}$ & $\begin{array}{c}\text { IN 02/11, IN } 10 / 10 \mathrm{e} \\
\text { IN } 12 / 08\end{array}$ & DN COPAM 74/04 & $\begin{array}{c}\text { Decretos Estaduais } \\
44.820 / 14 \text { e } 45.482 / 15 \\
\text { e Resoluções INEA } \\
\text { 52/12 e 53/12, Resolução } \\
\text { CONEMA 65/2015. }\end{array}$ & $\begin{array}{l}\text { Lei Estadual 997/76, } \\
\text { Decreto Estadual } \\
\text { 8.468/76 e SMA 54/04 }\end{array}$ \\
\hline $\begin{array}{c}\text { Terminologia } \\
\text { utilizada para } \\
\text { descrever tipos } \\
\text { simplificados de } \\
\text { licença ambiental }\end{array}$ & $\begin{array}{c}\text { Licença Simplificada } \\
\text { (LS) }\end{array}$ & $\begin{array}{l}\text { Autorização Ambiental de } \\
\text { Funcionamento (AAF), } \\
\text { Licença Prévia e de } \\
\text { Instalação concomitante } \\
\text { (LP/LI) e Licença de } \\
\text { Instalação e Operação } \\
\text { Concomitante (LIO) }\end{array}$ & $\begin{array}{l}\text { Licença Ambiental } \\
\text { Simplificada (LAS), } \\
\text { Licença Prévia e de } \\
\text { Instalação (LPI) e } \\
\text { Licença de Instalação e } \\
\text { de Operação (LIO) }\end{array}$ & $\begin{array}{c}\text { Não foi observada a } \\
\text { existência de termos } \\
\text { específicos para as } \\
\text { licenças, mas a CETESB } \\
\text { faz emissão concomitante } \\
\text { de três ou duas licenças } \\
\text { do tipo LP/LI/LO, LP/LI } \\
\text { e LI/LO, sobretudo nos } \\
\text { casos via SILIS }\end{array}$ \\
\hline $\begin{array}{c}\text { Terminologia } \\
\text { utilizada para } \\
\text { descrever estudos de } \\
\text { impacto ambiental } \\
\text { simplificados } \\
\end{array}$ & $\begin{array}{l}\text { Relatório Ambiental } \\
\text { Preliminar (RAP) e } \\
\text { Plano de Controle } \\
\text { Ambiental (PCA) }\end{array}$ & $\begin{array}{c}\text { Relatório de Controle } \\
\text { Ambiental (RCA) e Plano } \\
\text { de Controle Ambiental } \\
\text { (PCA) }\end{array}$ & $\begin{array}{l}\text { Relatório Ambiental } \\
\text { Simplificado (RAS) }\end{array}$ & $\begin{array}{l}\text { Relatório Ambiental } \\
\text { Preliminar (RAP) e } \\
\text { Estudo Ambiental } \\
\text { Simplificado (EAS). }\end{array}$ \\
\hline $\begin{array}{c}\text { Alternativas ao } \\
\text { modelo trifásico } \\
(\mathrm{LP}+\mathrm{LI}+\mathrm{LO})\end{array}$ & Monofásico (LS) & $\begin{array}{c}\text { Monofásico (AAF) ou } \\
\text { Bifásico (LP/LI + LO para } \\
\text { alguns casos) }\end{array}$ & $\begin{array}{l}\text { Monofásico (AAF) e } \\
\text { Bifásico (LP/LI + LO } \\
\text { para alguns casos) }\end{array}$ & $\begin{array}{l}\text { Monofásico (via SILIS) } \\
\text { e Bifásico (LP/LI + LO } \\
\text { para alguns casos) }\end{array}$ \\
\hline
\end{tabular}

FONTE: Os Autores. 
O conceito de licenciamento ambiental simplificado não está claramente definido nos estados pesquisados. O termo "simplificado", quando utilizado, pode trazer significados diferentes. Por exemplo, nem o Estado de Minas Gerais utiliza o termo "simplificado" para tratar dos procedimentos de licenciamento monofásicos. Já nos casos do Espírito Santo e do Rio de Janeiro, o termo "simplificado" fica explícito na Licença Simplificada (LS) e na Licença Ambiental Simplificada (LAS), respectivamente. Da mesma maneira, os estados do Rio de Janeiro e São Paulo utilizam o termo "simplificado" para qualificar alguns tipos de estudos ambientais, enquanto os estados de Minas Gerais e Espírito Santo, apesar de adotarem estudos "simplificados", adotam terminologia distinta.

Nos casos aqui analisados, os procedimentos simplificados tendem a ser aplicáveis, sobretudo, a projetos que tenham baixo potencial de impacto ou baixo impacto. Conforme mostra a Figura 2, os projetos de baixo potencial de impacto, quando não são dispensados de licenciamento ambiental, podem ser submetidos a processos mais simplificados de licenciamento, onde os estudos de impacto ambiental são dispensados.

Os critérios utilizados para definir os potenciais graus de impactos dos projetos ilustrados na Figura 2 podem variar significativamente. Con- forme analisaram Rocha \& Fonseca (2014), cada Estado da região sudeste adota critérios específicos, que podem incluir, por exemplo, porte, potencial poluidor, potência instalada, número de funcionários, fator de complexidade, etc., de modo que o enquadramento dos projetos varia significativamente entre jurisdições.

De maneira geral, nos enquadramentos das atividades e empreendimentos da região sudeste, a vulnerabilidade do meio ambiente parece ser marginalizada quando comparada a critérios de porte e potencial poluidor. No Espírito Santo, a IN 12/08 estabelece os critérios para que o empreendimento seja enquadrado na Licença Simplificada e, para tanto, leva em consideração se o empreendimento está localizado em Área de Proteção Permanente (APP) ou Unidade de Conservação. Em Minas Gerais, há uma menção, na DN COPAM 129/2008, sobre a importância de que o Zoneamento Ecológico Econômico (ZEE) seja utilizado como instrumento auxiliar para o licenciamento ambiental. No Rio de Janeiro, para que a LAS seja concedida, pode-se analisar diversos fatores, inclusive locacionais. Em São Paulo, a legislação menciona a possibilidade de observância de fatores locacionais para a definição dos tipos de licença e dos estudos ambientais. Todavia, essas "possibilidades regulatórias" não significam que, na prática, a vulnerabilidade do meio

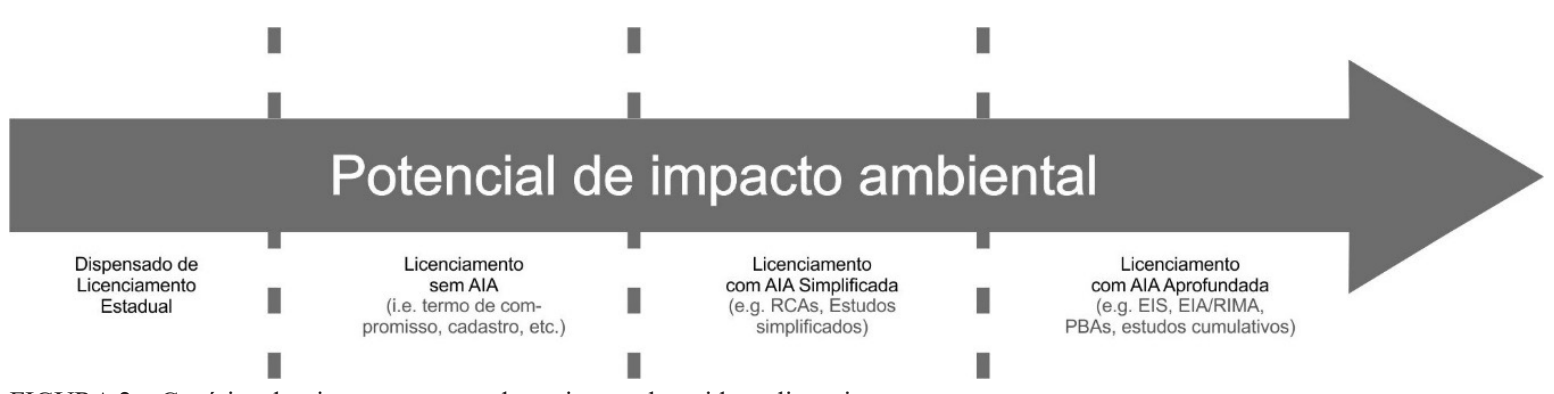

FIGURA 2 - Cenários de triagem e escopo de projetos submetidos a licenciamento.

FONTE: Adaptado de Rocha \& Fonseca (2014) 
ambiente esteja sendo observada nos enquadramentos dos modelos simplificados de licenciamento ambiental do sudeste. Dada a histórica dificuldade que o poder público brasileiro tem tido para montar sistemas de informação ambiental e zoneamentos ambientais, é de se especular que isto não esteja acontecendo de maneira satisfatória. Estudos futuros poderiam explorar melhor esta especulação.

\subsection{Potenciais implicações dos modelos simplificados de Licenciamento Ambiental}

Ficou claro nesta pesquisa que o nível de simplificação pode variar substancialmente dentro dos próprios estados e também entre eles. Não existe "um" único, mas diversos modelos de simplificação do licenciamento ambiental. A Figura 3 auxilia na compreensão dessa pluralidade, ao mostrar cinco diferentes "modelos" com níveis diferentes de exigência procedimental e documental. Os níveis mais baixos da Figura 3 representam o licenciamento ambiental desvinculado da AIA, ou seja, modelos de licenciamento ambiental em que o Estado autoriza uma atividade ou empreendimento sem exigência de estudo de impacto. O nível mais alto corresponde ao modelo convencional de licenciamento trifásico com exigência de EIA/RIMA, nos moldes das Resoluções CONAMA 01/86 e 237/97.

A AAF, de Minas Gerais, e a LS, do Espírito Santo, refletem modelos extremamente simplificados de licenciamento, correspondendo, portanto, ao nível mais baixo da Figura 3. Os modelos bifásicos de expedição concomitantes de mais de uma licença ambiental correspondem aos níveis intermediários. Modelos monofásicos ou bifásicos também podem ter graus diferenciados de simplificação, dependendo dos tipos e da quantidade de documentos e estudos solicitados.
A Figura 3 ajuda a ilustrar o fato de que a simplificação do licenciamento, por um lado, pode agilizar o processo, por meio da redução de trâmites e análises, bem como reduzir os custos do processo, com a minimização da contratação de projetos e estudos por parte dos empreendedores. Mas, por outro lado, os modelos simplificados de licenciamento podem diminuir o grau de precaução do processo decisório, aumentando os riscos de decisões equivocadas do Estado. Afinal, os modelos simplificados geram menos informação e estudos, além de oferecer menos tempo e oportunidades para a participação social. Sem a devida informação e input social, o poder público pode decidir pela aprovação de projetos que podem ter impacto ambiental significativo, ou pela reprovação de projetos que não tenham impacto ambiental significativo. Todavia, é mais razoável acreditar que o risco maior é de aprovar projetos que possam impactar negativamente o meio ambiente, dada a pressão por atividades econômicas no contexto do sudeste brasileiro.

Os modelos mais simplificados, ao se desvincularem da AIA, que é essencialmente um instrumento de avaliação "prévia", podem comprometer a observância do princípio da prevenção, que permeia a Política Nacional do Meio Ambiente. Este risco, para ser mitigado, dependeria da capacidade do Estado de fiscalizar, e eventualmente punir, civil e criminalmente, o cumprimento das licenças ambientais: um cenário improvável no curto prazo, dada a histórica dificuldade que o Estado brasileiro tem na aplicação de sanções ao descumprimento da legislação ambiental (IPEA, 2011).

Outra potencial consequência dos modelos simplificados de licenciamento ambiental é a aprovação de projetos de baixo potencial de impacto que não levem em consideração os efeitos cumulativos sinérgicos dos projetos no espaço e no 


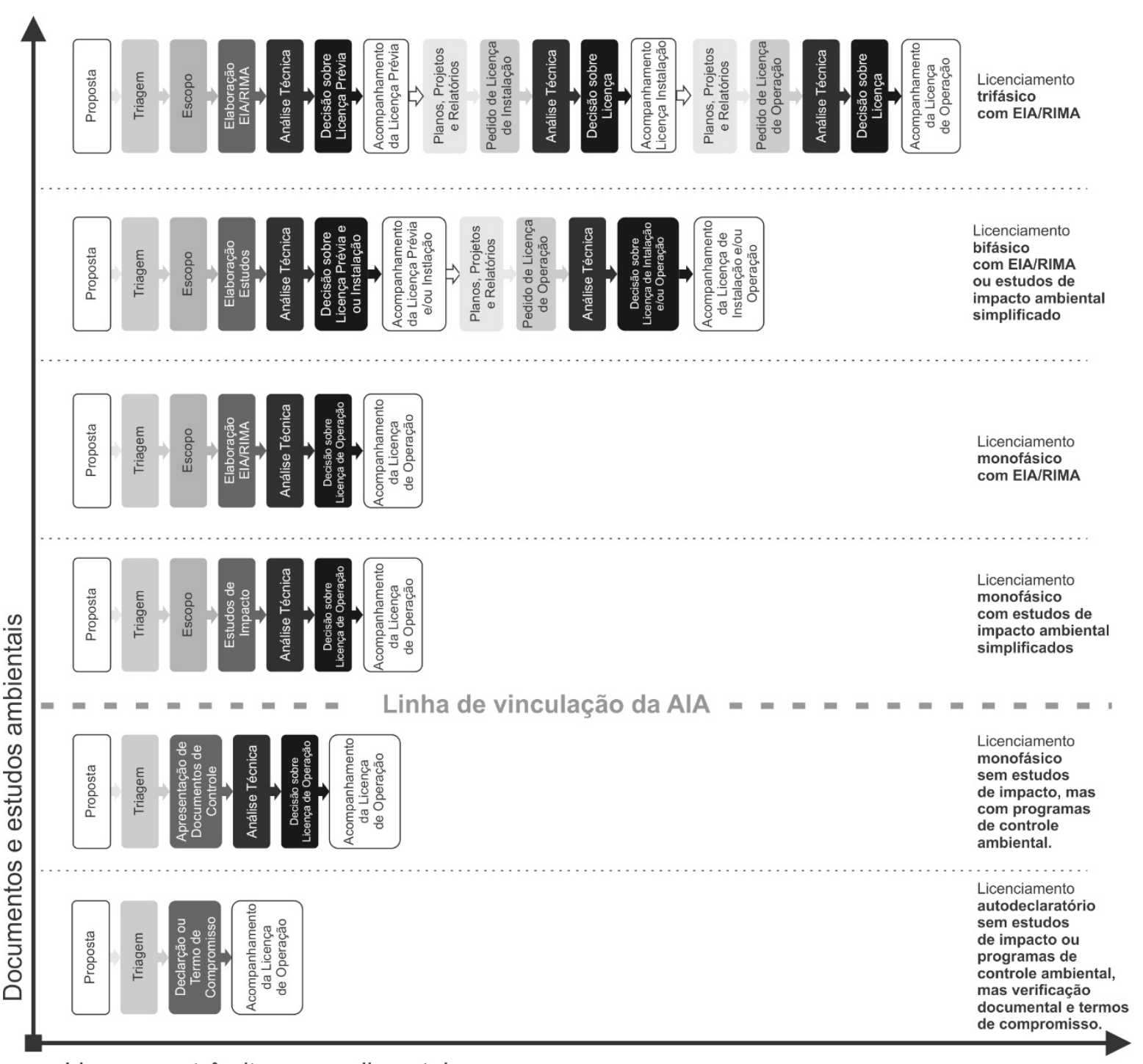

Licenças e trâmites procedimentais

FIGURA 3 - Graus de informação e procedimentos em modelos simplificados de licenciamento ambiental. FONTE: Adaptado de Fonseca (2015).

tempo. A análise de efeitos cumulativos e sinérgicos é mandatória nos casos de EIA/RIMA, mas, conforme identificado aqui, tende a ser dispensada nos modelos simplificados de licenciamento. A falta de análise ex-ante dos efeitos cumulativos e sinérgicos, caso não seja compensada por um planejamento e monitoramento do território e do uso do solo em escalas locais e regionais, poderá ocasionar aprovações de projetos que, apesar dos baixos potenciais de impacto, mostrem-se prejudiciais à sociedade e 
ao meio ambiente no médio e longo prazos. Além disso, a pluralidade de abordagens de triagem do licenciamento simplificado identificadas nesse estudo evidencia uma falta de padronização e consenso técnico em relação aos critérios de enquadramento prévio dos projetos de baixo potencial de impacto, uma situação que pode levar os órgãos ambientais a aplicarem procedimentos e estudos simplificados para projetos com alto potencial de impacto.

\section{Considerações finais}

O objetivo deste estudo foi analisar e comparar os conceitos e modelos de licenciamento ambiental estadual simplificado na região sudeste brasileira, de modo a entender em que medida tais licenciamentos podem afetar o processo decisório e o acompanhamento das licenças ambientais. As informações aqui levantadas permitem concluir que, apesar da diversidade de conceitos e modelos de licenciamento ambiental simplificados, todos de alguma forma tratam da redução de trâmites, estudos e análises no processo. A simplificação do licenciamento de ambiental pode contribuir para desvinculação da Avaliação de Impacto Ambiental do licenciamento ambiental, na medida em que este passa a ser conduzido sem o apoio daquele. Também ficou evidente que a simplificação pode diminuir o grau de precaução do processo, ao diminuir o volume de informações e ritos de análise e participação pública. Todavia, os procedimentos simplificados podem agilizar a concessão de licença e reduzir os custos do processo.

Nesta pesquisa, não foi possível emitir conclusões acerca da "efetividade" dos instrumentos simplificados. Para tal, seriam necessárias investi- gações acerca do desempenho ambiental dos projetos que foram implementados após a concessão de autorizações ou licenças ambientais obtidas de forma simplificada. Sugere-se que estudos futuros analisem esta questão, considerando os efeitos dos projetos aprovados em ritos simplificados em recortes temporais e geográficos mais amplos. Esta pesquisa também não analisou os modelos simplificados vigentes nos níveis federais e municipais, bem como em outros Estados e países. $\mathrm{O}$ fenômeno da simplificação é, obviamente, bem mais plural do que o capturado neste artigo. Espera-se que estudos futuros investiguem outras abordagens de simplificação.

Diante da crescente pressão industrial e da formação de passivos de processos de licenciamento nos órgãos públicos, é de se esperar um crescente interesse pela simplificação do licenciamento ambiental. Nos últimos meses, como citado aqui, os estados de Minas Gerais e Rio de Janeiro publicaram a Lei 21.972/16 e a Resolução CONEMA 69/15, respectivamente, que instauram novos modelos simplificados de licenciamento ambiental. Para que estas e outras iniciativas não signifiquem um retrocesso na política ambiental, será preciso investigar continuamente os desafios e as perspectivas da simplificação.

\section{Agradecimentos}

Os autores agradecem ao Conselho Nacional de Desenvolvimento Científico e Tecnológico (CNPq) pelo auxílio financeiro concedido através do processo 473772/2012-4. Este auxílio foi fundamental para a condução do projeto de pesquisa que resultou neste artigo e em outras publicações. 


\section{Referências}

ABEMA. Novas propostas para o licenciamento ambiental no Brasil. Brasília: Associação Brasileira de Entidades Estaduais de Meio Ambiente. 2013.

Aguilar, G. D. T. Análise do tempo de tramitação de processos de licenciamento ambiental: estudo de casos de termelétricas no estado de são paulo. São Paulo, Tese (Mestrado em Ciências da Engenharia Ambiental) - Escola de Engenharia, Universidade de São Paulo, 2008.

Banco Mundial. Licenciamento ambiental de empreendimentos hidrelétricos no Brasil: uma contribuição para o debate. Brasília: Banco Mundial, 2008.

Bond, A.; Pope, J.; Morrison-Saunders, A.; Retief, F.; Gunn, J. A. E. Impact assessment: Eroding benefits through streamlining? Environmental Impact Assesment Review, 45, 46-53, 2014.

Borges, A. Presidente do IBAMA reconhece lentidão. $O$ Estado de São Paulo, São Paulo, 30 de maio de 2015. Diponível em: <http://economia.estadão.com.br/notícias/ geral,presidente-do-ibama-reconhece-lentidao.1697459>. Acesso em: 04 jun. 2015.

Brasil. Lei $n^{\circ} 6.938$, de 31 de agosto de 1981. Dispõe sobre a Política Nacional do Meio Ambiente, seus fins e mecanismos de formulação e aplicação, e dá outras providências. Diário Oficial da União, Brasília, 02 de setembro de 1981. Disponível em: $<$ http://www.planalto.gov.br/ccivil_03/leis/ 16938.htm >. Acesso em: 14 de março de 2014.

Brasil. Conselho Nacional do Meio Ambiente. Resolução $n^{\circ}$ 01/86, de 23 de janeiro de 1986. Diário Oficial da União, Brasília, 23 de janeiro. 1986.

Brasil. Conselho Nacional do Meio Ambiente. Resolução $n^{\circ}$ 237, de 19 de dezembro de 1997. Diário Oficial da União, Brasília, 19 dez. 1997.

Brasil. Portaria 420, de 26 de outubro de 2011. Dispõe sobre procedimentos a serem aplicados pelo Instituto Brasileiro do Meio Ambiente e dos Recursos Naturais Renováveis - IBAMA - na regularização e no licenciamento ambiental das rodovias federais. Brasília: Ministério do Meio Ambiente 2011a.

Brasil. Portaria 421, de 26 de outubro de 2011. Dispõe sobre o licenciamento e a regularização ambiental federal de sistemas de transmissão de energia elétrica e dá outras providências. Brasília: Ministério do Meio Ambiente 2011b.

Brasil. Portaria 422, de 26 de outubro de 2011. Dispõe sobre procedimentos para o licenciamento ambiental federal de atividades e empreendimentos de exploração e produção de petróleo e gás natural no ambiente marinho e em zona de transição terra-mar. Brasília: Ministério do Meio Ambiente 2011c.

Brasil. Portaria Interministerial 423, de 26 de outubro de 2011. Institui o Programa de Rodovias Federais Ambientalmente Sustentáveis para a regularização ambiental das rodovias federais. Brasília: Ministério do Meio Ambiente e Ministério dos Transportes, 2011d.

Brasil. Portaria Interministerial MMA/SEP/PR 425, de 26 de outubro de 2011. Institui o Programa Federal de Apoio à Regularização e Gestão Ambiental Portuária - PRGAP - de portos e terminais portuários marítimos, inclusive os outorgados à Companhia Docas, vinculadas à $\mathrm{SEP} / \mathrm{PR}$. Brasília: Ministério do Meio Ambiente e Secretaria de Portos da Presidência da República, 2011e.

Brasil. Portaria Interministerial $n^{\circ} 419$, de 26 de outubro de 2011. Regulamenta a atuação dos órgãos e entidades da Administração Pública Federal envolvidos no licenciamento ambiental, de que trata o art. 14 da Lei $n^{\circ} 11.516$, de 28 de agosto de 2007. Brasília: Ministério do Meio Ambiente, Ministério da Justiça, Minisério da Cultura e Ministério da Saúde, 2011f.

Câmara dos Deputados. Debatedores criticam prejuízos com demora na expedição de licenças ambientais. 2015. Disponível em:<http://www2.camara.leg.br/camaranoticias/ noticias/MEIO-AMBIENTE/487902-DEBATEDORES-CRITICAM-PREJUIZOS-COM-DEMORA-NA-EXPEDICAO-DE-LICENCAS-AMBIENTAIS.html>. Acesso em: 20 jun. 2015.

CETESB - Companhia Ambiental do Estado de São Paulo (São Paulo). Licenciamento. 2014a. Disponível em: $<$ http:// licenciamento.cetesb.sp.gov.br/cetesb/aia_quem.asp $>$. Acesso em: 20 abr. 2014.

CETESB - Companhia Ambiental do Estado de São Paulo (São Paulo). SILIS: Sistema de Licenciamento Simplificado. 
2014b. Disponível em: $<$ http://silis.cetesb.sp.gov.br/index. php>. Acesso em: 20 abr. 2014.

CNI. Empresas enfrentam dificuldades no licenciamento ambiental. Sondagem Especial da Confederação Nacional da Indústria, 5(2), 1-8, 2007.

CNI. Mais agilidade e eficácia para o licenciamento. 2011. Disponível em: <http://www.cni.org.br/portal/data/pages/ FF8080812A7DEC2C012A8580E9C03096.htm $>$. Acesso em: 15 nov. 2011.

CNI. Proposta da indústria para o aprimoramento do Licenciamento Ambiental. Brasília: Confederação Nacional da Indústria (CNI), 2013.

CONEMA - Conselho Estadual de Meio Ambiente (Rio de Janeiro). Resolução CONEMA n. 69, de 16 de dezembro de 2015. Estabelecido procedimento simplificado para o licenciamento ambiental. Rio de Janeiro/RJ, 2015.

CONSEMA - Conselho Estadual de Meio Ambiente (Espírito Santo). Resolução CONSEMA $n^{\circ}$ 001, de 19 de março de 2008. Dispõe sobre a redefinição dos procedimentos para o licenciamento ambiental dos empreendimentos enquadrados como classe simplificada tipo "S" nos termos da legislação em vigor. Cariacica/ES, 19 de março de 2008.

Dantas, M. Acúmulo de processos no Idema já passa de cinco mil. Tribuna do Norte, 2014.

Dietz, T.; Stern, P. C. Public Participation in Environmental Assessment and Decision-making. Washington: The National Academic Press, 2008.

Fonseca, A. A avaliação de impacto e o seu vínculo com o licenciamento ambiental. In: Ribeiro, J. C. J. (Org..). Licenciamento ambiental: herói, vilão ou vítima? Belo Horizonte: Arraes Editores, 2015. p. 27-39.

Goiânia, P. D. AMMA discute ações para informatizar licenciamento ambiental. 2015. Disponível em: <http:// www.goiania.go.gov.br/portal/pagina/?pagina=noticias\&s $=1 \& \mathrm{tt}=$ not\&cd=6038\&fn=true $>$. Acesso em: 27 fev. 2015 .

Governo do Espírito Santo. IEMA firma parceria para agilizar licenciamento ambiental. 2013. Disponível em: $<$ http://www. es.gov.br/Noticias/165530/iema-firma-parceria-para-agilizar-licenciamento-ambiental.htm>. Acesso em: 31 out. 2013.

Hofmann, R. M. Gargalos do licenciamento ambiental federal no Brasil. Brasília: Consultoria Legislativa, Câmara dos Deputados, 2015.
IBAMA. Sistema informatizado de licenciamento ambiental federal. 2015. Disponível em: <https://www.ibama.gov.br/ licenciamento $>$. Acesso em: 11 maio 2015.

IEMA - Instituto Estadual de Meio Ambiente e Recursos Hídricos (Espírito Santo). Instrução Normativa $n^{\circ} 12$, de 18 de setembro de 2008. Dispõe sobre a classificação de empreendimentos e definição dos procedimentos relacionados ao licenciamento ambiental simplificado. Cariacica/ES, 2008. Disponível em: <http://www.meioambiente.es.gov. br/>. Acesso em: 20 abr. 2014.

IEMA - Instituto Estadual de Meio Ambiente e Recursos Hídricos (Espírito Santo). Instrução Normativa ${ }^{\circ} 10$, de 28 de dezembro de 2010. Dispõe sobre o enquadramento das atividades potencialmente poluidoras e/ou degradadoras do meio ambiente com obrigatoriedade de licenciamento ambiental junto ao IEMA e sua classificação quanto a potencial poluidor e porte. Cariacica/ES, 2010. Disponível em: $<$ http:// www.meioambiente.es.gov.br/>. Acesso em: 10 abr. 2014.

IEMA - Instituto Estadual de Meio Ambiente e Recursos Hídricos (Espírito Santo). Licenciamento Ambiental. 2014. Disponível em: $<$ http://www.meioambiente.es.gov. br/default.asp?pagina=17996>. Acesso em: 10 abr. 2014.

INEA. Resolução INEA $n^{\circ}$ 52, de 19 de março de 2012. Estabelece os novos códigos para o enquadramento de empreendimentos e atividades poluidores ou utilizadores de recursos naturais, bem como os capazes de causar degradação ambiental, sujeitos ao licenciamento ambiental. Disponível em: <http://www.rcambiental.com.br/Atos/ver/ RESL-INEA-RJ-52-2012/>. Acesso em: 20 abr. 2014 .

INEA. Resolução INEA $n^{\circ}$ 53, de 27 de março de 2012. Estabelece os novos critérios para determinação do porte e potencial poluidor dos empreendimentos e atividades poluidores ou utilizadores de recursos naturais, bem como os capazes de causar degradação ambiental, sujeitos ao licenciamento ambiental. Disponível em: <http://www. rcambiental.com.br/Atos/ver/RESL-INEA-RJ-53-2012/>. Acesso em: 20 de abr. 2014 .

INEA. Licenciamento Ambiental. 2014. Disponível em: $<$ http://www.inea.rj.gov.br/fma/licenciamento-apresentacao.asp>. Acesso em: 20 abr. 2014.

IPEA. Direito Ambiental Brasileiro: Lei dos Crimes Ambientais. Brasília: Instituto de Pesquisa Econômica e Aplicada (IPEA), 2011. 
Kirchhoff, D.; Tsuji, L. J. S. Reading between the lines of the 'Responsible Resource Development' rhetoric: the use of omnibus bills to 'streamline' Canadian environmental legislation. Impact Assessment and Project Appraisal, 32(2), 108-120, 2014.

Kirchhoff, D.; Montano, M.; Ranieri, V. E. L.; De Oliveira, I. S. D.; Doberstein, B.; de Souza, M. P. Limitations and drawbacks of using Preliminary Environmental Reports (PERs) as an input to Environmental Licensing in São Paulo State: a case study on natural gas pipeline routing. Environmental Impact Assessment Review, 27(4), 301-318, 2007.

Minas Gerais. Conselho Estadual de Política Ambiental (Minas Gerais). Deliberação Normativa Copam n ${ }^{\circ}$ 74, de 09 de setembro de 2004. Estabelece critérios para classificação, segundo o porte e potencial poluidor, de empreendimentos e atividades modificadoras do meio ambiente passíveis de autorização ou de licenciamento ambiental no nível estadual, determina normas para indenização dos custos de análise de pedidos de autorização e de licenciamento ambiental, e dá outras providências. Diário do Executivo de Minas Gerais, Belo Horizonte, 02 de outubro de 2004.

Minas Gerais. Lei $n^{\circ}$ 21.972, de 21 de janeiro de 2016. Dispõe sobre o Sistema Estadual de Meio Ambiente e Recursos Hídricos - Sisema - e dá outras providências. Belo Horizonte: Governo do Estado de Minas Gerais, 2016.

Montaño, M.; Souza, M. P. D. A viabilidade ambiental no licenciamento de empreendimentos perigosos no Estado de São Paulo. Engenharia Sanitária e Ambiental, 13(4), 435-442, 2008.

Moraes. A. M. L. A Autorização Ambiental de Funcionamento como instrumento de regularização ambiental em Minas Gerais para a atividade de extração e cascalho para a construção civil. Ouro Preto, Dissertação (Mestrado em Sustentabilidade Socioeconômica e Ambiental) - Núcleo de Pesquisas e Pós-Graduação em Recursos Hídricos, Universidade Federal de Ouro Preto (MG), 2013.

Moreira, I. V. D. EIA in Latin American. In: Wathern, P. (Org.) Environmental impact assessment: theory and practice. London: Unwin Hyman, 1988. p. 239-253.

Morgan, R. K. Environmental impact assessment: the state of the art. Impact Assessment and Project Appraisal, 30(1), 5-14, 2012.
Morrison-Saunders, A.; Arts, J. Assessing impact: handbook of EIA and SEA follow-up. London: Earthscan, 2004.

O Tempo. Governo quer agilizar licenças ambientais. 2015. Disponível em: $<$ http://www.otempo.com.br/governo-quer-agilizar-licen\%C3\%A7as-ambientais-1.1021099>. Acesso em: 08 abr. 2015.

Pereira, C. Licença ambiental demora em média 909 dias no Rio Grande do Sul: ZH Notícias, 2015.

Porto, B. MPF questiona licença rápida em Minas. Hoje em Dia, Belo Horizonte, p. 10, 20 de novembro de 2010.

Porto, B. Sublicenciamento está suspenso em MG. Hoje em Dia, Belo Horizonte, p. 13, 04 de janeiro de 2011.

Prefeitura de Manaus. Licenciamento ambiental reduz passivo e aumenta número de licenças em 2010. 2010. Disponível em: <http://semmas.manaus.am.gov.br/licenciamento-ambiental-reduz-passivo-e-aumenta-numero-de-licencas-em-2010/>. Acesso em: 30 dez. 2010.

Procuradoria da República do Ceará. $M P F$ requisita ao Ibama embargo em obras com licenciamento ambiental simplificado. Fortaleza: Ministério Público Federal no Ceará. 2011.

Ribeiro, I. C. S. Licenciamento simplificado: uma análise crítica aplicada à realidade das micro e pequenas empresas da Bahia. Salvador (BA), Dissertação (Mestrado em Gerenciamento e Tecnologias Ambientais no Processo Produtivo) - Departamento de Engenharia Ambiental, Universidade Federal da Bahia, 2004.

Ribeiro, J. C. J. Mota, M. L. R. O significativo impacto ambiental. In: Ribeiro, J. C. J. (Org.). Licenciamento Ambiental: herói, vilão ou vítima? Cap. 3. Belo Horizonte: Arraes Editores, 2015. p. 42-50.

Ribeiro, B. Q.; Pinheiro, A. C. D. Participação popular no licenciamento de atividades causadoras de significativo impacto ambiental. Revista do Direito Público, 6(1), 232246, 2011.

Rio de Janeiro (Estado). Decreto $n^{\circ} 44.820$, de 02 de junho de 2014. Dispõe sobre o Sistema de Licenciamento Ambiental - SLAM e dá outras providências. Casa Civil, Rio de Janeiro, 03 de dezembro de 2014.

Rocha, C.; Fonseca, A. EIA screening criteria in Brazil: A logical test? Impact Assessment for Social and Economic 
Development: 34th Annual Conference of the International Association for Impact Assessment. Viña del Mar, 2014.

Rodrigues, G. S. S. C. A análise interdisciplinar de processos de licenciamento ambiental no Estado de Minas Gerais: conflitos entre velhos e novos paradigmas. Sociedade \& Natureza, 22(2), 267-282, 2010.

SAE. Licenciamento Ambiental - Documento para Discussão (Versão preliminar). Brasília: Secretaria de Assuntos Estratégicos da Presidência da República, 2009.

Sánchez, L. E. Development of Environmental Impact Assessment in Brazil. UVP Report, 27, 193-200, 2013.

São Paulo. Decreto $n^{\circ}$ 47.397, de 04 de setembro de 2002. Dá nova redação ao título $\mathrm{V}$ e ao anexo 5 e acrescenta os anexos 9 e 10 ao regulamento da Lei $\mathrm{n}^{\circ} 997$, de 31 de maio de 1976 , aprovado pelo Decreto $n^{\circ} 8.468$, de 8 de setembro de 1976, que dispõe sobre a prevenção e o controle da poluição do meio ambiente. São Paulo: Governo do estado de São Paulo, 2002.

São Paulo. Secretaria do Meio Ambiente. Resolução SMA $n$. 54/2004. Dispõe sobre procedimentos para o licenciamento ambiental no âmbito da Secretaria do Meio Ambiente. São Paulo, 2004.

SEBRAE. Licenciamento Ambiental Simplificado Especial (LASE) voltado para as micro e pequenas empresas. 2011. Disponível em: <http://www.biblioteca.sebrae.com.br/bds/ BDS.nsf/08C302077DF2BF23832574C00069CAB4/\$File/ NT00038D9A.pdf>. Acesso em: 27 abr. 2012.
SEMAD. Superintendências Regionais de Regularização Ambiental. 2014. Disponível em: <http://www.semad. mg.gov.br/suprams-regionais>. Acesso em: 20 abr. 2014.

Senécal, P. et al. Principles of Environmental Impact Assessment Best Practice. 1999. Disponível em: <http://www.iaia. org/publicdocuments/special-publications/Principles $\% 20$ of\%20IA_web.pdf $>$. Acesso em: January, 2011.

SILIS - Sistema de Licenciamento Simplificado. Critério para classificação de empreendimentos de baixo potencial poluidor. 2010. Disponível em: <http://silis.cetesb.sp.gov. br/pdf_criterio/criterios_para_classificacao_SILIS.pdf $>$. Acesso em: 27 abr. 2012.

Tudo Sobre Floripa. Fatma tem 20 dias para melhorar o licenciamento ambiental em Santa Catarina. 2014. Disponível em: <http://www.tudosobrefloripa.com.br/index.php/ desc_noticias/fatma_tem_20_dias_para_melhorar_o_licenciamento_ambiental_em_santa_catarina $>$. Acesso em: 19 mar. 2014.

Viana, M. B. Licenciamento Ambiental de Minerações em Minas Gerais: novas abordagens de gestão. Dissertação (Mestrado) - Centro de Desenvolvimento Sustentável, Universidade de Brasília, Brasília, 2007.

Viana, M. B.; Bursztyn, M. A. A. Regularização ambiental de mineração em Minas Gerais. Revista Escola de Minas, 63(2), 363-369. 2010.

Wathern, P. Environmental Impact Assessment: Theory and Practice. London and New York: Routledge/Taylor \& Francis Group, 1990. 